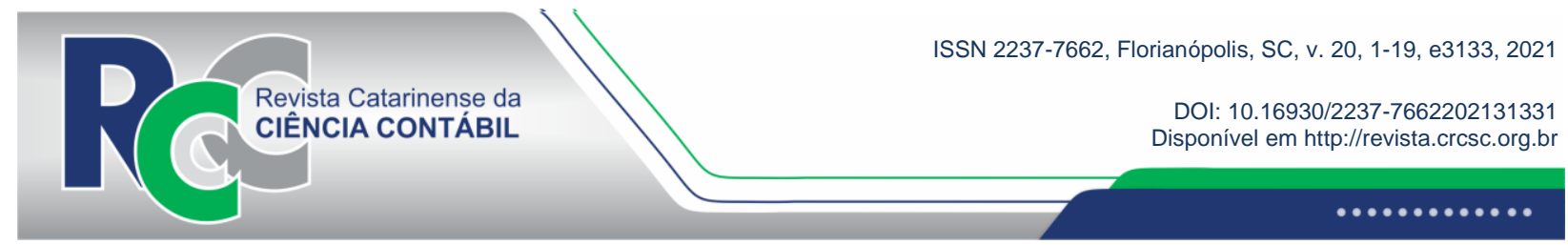

\title{
PERCEPÇÕES DOCENTES E ÀS ESTRATÉGIAS DE ENSINO- APRENDIZAGEM DURANTE O ISOLAMENTO SOCIAL MOTIVADO PELA COVID-19
}

\author{
PROFESSORS' PERCEPTIONS AND TEACHING-LEARNING STRATEGIES \\ DURING SOCIAL ISOLATION MOTIVATED BY COVID-19
}

\author{
DANIELA CARINE SCHMITT \\ Universidade Comunitária da Região de Chapecó. Endereço: Rua \\ Alberto Dalcanalle, 152 | Centro | 89900-000 | São Miguel do Oeste/SC \\ | Brasil. \\ (D) http://orcid.org/0000-0002-4599-1384 \\ danielacarine@yahoo.com.br
}

\section{DIONES KLEINIBING BUGALHO}

Universidade Comunitária da Região de Chapecó. Endereço: Rua Aimoré, 55 | Centro | 85505-170 | Pato Branco/PR | Brasil.

(1) http://orcid.org/0000-0002-4636-5086

diones.bugalho@unochapeco.edu.br

\section{SILVANA DALMUTT KRUGER}

Universidade Comunitária da Região de Chapecó. Endereço: Rua Benjamin Constant, 265| Centro | 89801-070 | Chapecó/SC | Brasil.

(D) http://orcid.org/0000-0002-3353-4100

silvanak@unochapeco.edu.br

\section{RESUMO}

O objetivo deste texto é identificar as principais estratégias do processo de ensino-aprendizagem, bem como as percepções dos docentes durante o período de isolamento social no contexto da pandemia gerada pela Covid-19. A amostra do estudo é composta por 52 docentes dos cursos de Administração, Ciências Contábeis e Ciências Econômicas, atuantes em quatro instituições de ensino superior da região Sul do Brasil. O levantamento realizado por meio de questionário, compondo 32 questões, coletou a identificação dos respondentes; as percepções do processo de ensino e as estratégias de ensino-aprendizagem utilizadas a partir da inserção das aulas de forma remota, como alternativa no período de isolamento social. Quanto ao tratamento dos dados, empregou-se a estatística descritiva e o teste estatístico de Mann-Whitney, a análise é de cunho quantitativo. Os resultados evidenciam que, para $96 \%$ dos pesquisados, as disciplinas ocorreram de forma remota; $92 \%$ indicam adaptações pedagógicas; e $76 \%$ responderam que a instituição ofereceu capacitações. As principais estratégias de ensino utilizadas no período de isolamento social são: aulas expositivas com apresentação de conteúdo em slides (98\%); exercícios com

Editado em português e inglês. Versão original em Português.

Apresentado no USP International Conference in Accounting, São Paulo, 2020.

Recebido em 13/1/2021. Revisado em 4/2/2021. Aceito em 1/3/2021 pelos Prof. Dr. Sérgio Murilo Petri (Editor-Chefe) e Prof. Dr. Sandro Vieira Soares (Editor Adjunto). Publicado em 19/3/2021.

Copyright (C) 2021 RCCC. Todos os direitos reservados. É permitida a citação de parte de artigos sem autorização prévia, desde que identificada a fonte. 
resolução (90\%); estudo de casos (69\%); e pesquisas/leituras orientadas sobre o conteúdo (52\%). A análise estatística evidencia que os docentes que utilizaram de problematização/casos de ensino, debates e uso de jogos, acreditam ter alcançado os objetivos de ensino-aprendizagem. Na percepção de 54\% dos docentes, as aulas realizadas de forma remota não representam prejuízos no processo de ensino-aprendizagem dos estudantes e atingiram os objetivos. De forma geral, os resultados demonstram adaptação das aulas presenciais ao formato remoto, bem como os achados sugerem a importância da inserção das tecnologias como estratégias de ensino, independentemente de o modelo ser ou não presencial.

Palavras-chave: Estratégias de ensino-aprendizagem. Covid-19. Ensino no isolamento social.

\begin{abstract}
The purpose of this text is to identify the main strategies of the teaching-learning process, as well as the perceptions of professors during the period of social isolation in the context of the pandemic generated by Covid-19. The study sample consists of 52 professors from the Administration, Accounting, and Economic Sciences courses, working in four higher education institutions in the southern region of Brazil. The survey carried out through a questionnaire comprising 32 questions, collected the respondents' identification, the perceptions of the teaching process, and the teaching-learning strategies used from the insertion of classes remotely as an alternative in the social isolation period. As data treatment, descriptive statistics, and the Mann-Whitney statistical test were used, the analysis is quantitative. The results show that, for $96 \%$ of those surveyed, the disciplines took place remotely; $92 \%$ indicate pedagogical adaptations, and $76 \%$ responded that the institution offered training. The main teaching strategies used in the period of social isolation are: expository classes with the presentation of content on slides (98\%); exercises with resolution (90\%); case study (69\%); and contentoriented research/reading (52\%). The statistical analysis shows that professors who used problematization/teaching cases, debates, and games believe they have achieved the teachinglearning objectives. In the perception of 54\% of professors, classes held remotely do not represent losses in students' teaching-learning process and have achieved their objectives. In general, the results demonstrate adaptation of face-to-face classes to the remote format. The findings suggest the importance of inserting technologies as teaching strategies, regardless of whether the model is face-to-face or not.
\end{abstract}

Keywords: Teaching-learning strategies. Covid-19. Teaching in social isolation.

\title{
1 INTRODUÇÃO
}

O atual cenário do ensino superior diante do isolamento social gerado pela pandemia da Covid-19, doença causada por uma variação do vírus coronavírus SARS-CoV-2, a qual apresenta potencial de contágio elevado, motivou a Organização Mundial da Saúde (OMS) a considerar o status da doença para pandemia (Arora \& Srinivasan, 2020; Sun, Qiu, Huang \& Yang, 2020). Além dos aspectos relacionados à saúde, a pandemia modificou a rotina de todos os segmentos econômicos mundiais. Os reflexos nos negócios, na geração de renda e nos empregos são variáveis econômicas afetadas, assim como no segmento educacional - estima-se que a pandemia afetou cerca de $87 \%$ dos estudantes (Unesco, 2020).

$\mathrm{O}$ avanço da pandemia fez que o mundo praticamente estagnasse. Pela necessidade de distanciamento social, as atividades mais dependentes do fluxo e da concentração de pessoas tiveram impacto imediato, como é o caso da educação superior presencial (Rossoni, 2020). Neste 
contexto, foram necessárias adaptações das instituições e dos profissionais da educação para criação de estratégias de ensino-aprendizagem visando manter a regularidade das atividades de ensino (Lall \& Singh, 2020).

Embora a última década tenha sido marcada por intensas modificações nas metodologias de ensino-aprendizagem, especialmente no ensino superior (Taraban, Rynearson, \& Kerr, 2000; Tinajero, Lemos, Araújo, Ferraces, \& Páramo, 2012; Hilliger et al., 2020), houve mudanças e a inserção do ensino a distância (EaD) (Miles, Mensinga, \& Zuchowski, 2018), o qual aumentou significativamente a formação de estudantes de vários segmentos da educação (Ramdass \& Masithulela, 2016).

As instituições de ensino superior (IES) são responsáveis pela propagação do conhecimento na sociedade, tanto pela condição de formação de profissionais, que serão agentes de transformação nas empresas, como pela condição de formação de opinião e de novos profissionais que serão docentes. Nesse sentido, as IES têm o compromisso na formação de habilidades humanas, cognitivas e no desenvolvimento de competências cívicas (Kruger, Zanella, Barichello, \& Petri, 2018; Zanella, Kruger, \& Barichello, 2019).

No Brasil em 2019, encontravam-se matriculados no ensino superior 8,6 milhões de estudantes. Destes, $71,6 \%$ em cursos de graduação na modalidade presencial, o que equivale a 6,2 milhões de estudantes, enquanto $76 \%$ das matrículas ocorreram em instituições de ensino privadas (Agência Brasil, 2020). As principais estratégias que diferem do ensino presencial é a motivação para a leitura de textos em ambientes virtuais de aprendizagem, além da autonomia dos estudantes em relação às etapas de ensino-aprendizagem (Amante, 2011).

No atual contexto social, o ambiente do ensino presencial foi afetado por decretos governamentais que restringem a execução das aulas de forma presencial. Tal condição exigiu das IES a criação de estratégias de ensino para adequar o ambiente de aprendizagem à forma remota/virtual emergencial, similar ao modelo da EaD. O estado de Santa Catarina, por meio dos Decretos $n^{\circ}$ 509/2020 e no 525/2020 (Governo do Estado de Santa Catarina, 2020), estabeleceu a suspensão das aulas presenciais em todos os níveis no estado e a utilização de plataformas para atender à condição do ensino remoto emergencial para continuação do calendário letivo, o qual sugere a utilização de estratégias de ensino distintas das presenciais, visando suprir as necessidades da estrutura de ensino realizada de forma remota.

Para o educador, é de suma importância a compreensão da educação focada no estudante, o que não representa que o educador desempenha função de menor relevância (Mendoza, Burbano, \& Valdivieso, 2019). Assim como no ensino presencial, o professor continua tendo papel relevante no contexto remoto emergencial, pois é figura essencial para criar, estruturar e animar experiências de aprendizagem. Especialmente quando as atividades são realizadas de forma síncrona, sua atuação como mediador do processo de ensino-aprendizagem contribui na qualificação e na formação dos estudantes (Miles et al., 2018).

A necessidade do ensino remoto para atender ao contexto de emergência provocado pela pandemia da Covid-19 não deve ser confundida com o aprendizado on-line, embora, durante o período de crise, a maioria das instituições e dos professores terem precisado se adaptar ao ensino remoto de emergência, o que exigiu mais planejamento e atenção na preparação das atividades, em infraestrutura e tecnologias, política educacional e recursos para assegurar a continuidade educacional (Barbour et al., 2020).

Diante do contexto apresentado, a problemática de pesquisa visa responder: quais as principais estratégias do processo de ensino-aprendizagem utilizadas pelos docentes durante o período de isolamento social no contexto da pandemia gerada pela Covid-19? O objetivo é identificar as principais estratégias do processo de ensino-aprendizagem, bem como as percepções dos docentes durante o período de isolamento social no contexto da pandemia gerada pelo Covid-19. 
Justifica-se a importância da pesquisa pelos reflexos na estrutura educacional do ensino superior no cenário atual instaurado pelo contexto da pandemia da Covid-19 (Arora \& Srinivasan, 2020; Sun et al., 2020). Esses reflexos motivam que os educadores adotem novas percepções quanto ao seu papel na condução da busca de soluções para sanar as dificuldades de aprendizagens, ocasionadas pelas adaptações das aulas remotas (Abmes, 2020). A amostra do estudo é composta por 52 docentes dos cursos de Administração, Ciências Contábeis e Ciências Econômicas, atuantes em quatro instituições de ensino superior da região Sul do Brasil, as quais abarcam o universo de 1.510 estudantes. Pondera-se que as referidas instituições realizaram adaptações ao modelo de ensino presencial para o modelo remoto emergencial, diferentemente das instituições de ensino federais, que suspenderam as atividades de ensino no ano de 2020.

O estudo apresenta as percepções dos docentes da área de gestão e negócios, observando as mudanças do processo de aprendizagem e das estratégias de ensino utilizadas, ponderando que o ensino presencial foi afetado pelas restrições de isolamento, exigindo adaptações para o ambiente virtual, sendo que as aulas presenciais passaram a ser executadas de forma remota, autorizadas pelo Ministério da Educação (2020), diante da pandemia da Covid-19. Num curto período de adaptação, as instituições e os docentes precisaram ajustar conteúdo e estratégias de ensino-aprendizagem, visando manter o cronograma das aulas remotas emergenciais (Barbour et al., 2020). Nessa conjuntura, o estudo apresenta como aspecto diferencial as percepções dos docentes quanto às adaptações das estratégias de aprendizagem no contexto remoto emergencial e o impacto das aulas remotas no processo de ensino.

\section{ESTRATÉGIAS DE ENSINO-APRENDIZAGEM E SUAS AVALIAÇÕES}

O termo "estratégias de ensino" pode ser entendido como a junção de meios utilizados pelos docentes no desenvolvimento do processo de ensino vinculado às atividades e aos resultados esperados por elas (Anastasiou \& Alves, 2004). Na articulação do ensinoaprendizagem em sala de aula, vários fatores podem influenciar nos resultados pretendidos, entre eles: condições da estrutura de ensino, condições de trabalho dos professores, condições socioeconômicas dos alunos, os recursos disponíveis e as estratégias de ensino (Mazzioni, 2013; Stobaugh, R., \& Everson, K. (2019).

As estratégias de ensino empregadas pelos docentes no dia a dia são outro elemento relevante, as quais devem ser desenvolvidas a fim de sensibilizar e instigar os discentes no processo de aprendizado, evidenciando o papel do professor e dos estudantes com a formação (Ali \& Syed, 2020). De modo a estabelecer relações interpessoais com os acadêmicos, de maneira que a relação ensino-aprendizagem seja articulada de forma capaz de satisfazer os objetivos do processo e que os métodos utilizados instiguem o desenvolvimento criativo dos acadêmicos, destaca-se a relevância do papel dos docentes para estimular a emoção dos alunos, instigar reflexões e a formação de habilidades (Silva, 2019). A forma com que o docente planeja as atividades e utiliza estratégias de ensino é um fator relevante para condicionar a reação dos estudantes e, consequentemente, reflete na aprendizagem (Oliver, 1999; Oliveira, 2017).

$\mathrm{Na}$ literatura, são encontradas evidências de distintas classificações de estratégias de aprendizagem. A mais utilizada provém de duas vertentes principais: a) cognitivas; e b) metacognitivas (Boruchovitch, \& Santos, 2006). As estratégias cognitivas englobam uma família de métodos gerais que os acadêmicos utilizam para trabalhar e compreender certo conteúdo das aulas e textos das disciplinas (Taraban et al., 2000).

As estratégias de ensino centradas no aluno ou aquelas centradas no professor precisam contribuir com os objetivos cognitivos e afetivos do ensino. Além disso, as estratégias de ensino para a prática científica, a combinação de estratégias voltadas para a experimentação e a 
discussão de problemas são estratégias de ensino utilizadas para atingir os objetivos cognitivos e afetivos do ensino (Halawa, Hsu, Zhang, Kuo, \& Wu, 2020, Murray, 2019).

A utilização de metodologias de ensino deve considerar que a forma pela qual o aluno aprende não é um ato descrito como isolado ou escolhido por acaso, sem conhecimento prévio dos conteúdos trabalhados ou das habilidades necessárias para a execução e as metas a serem alcançadas (Silva, 2019). As estratégias conhecidas e recomendadas pelos profissionais da educação convergem com as estratégias dos profissionais de outras áreas, embora possam receber nomenclaturas diferentes (Oliveira, 2017; Ali \& Syed, 2020).

No ambiente do ensino presencial, o foco está direcionado às metodologias de ensino; diferentemente, no ambiente da $\mathrm{EaD}$, o foco está nos alunos e nas ferramentas de ensino (Miles et al., 2018, Lall \& Singh, 2020). Com essas diferenças evidentes, as estratégias de ensinoaprendizagem se tornam protagonistas no sentido de maximizar o resultado do processo de ensino-aprendizagem. Além disso, as avaliações também precisam ser redimensionadas ao contexto do ambiente de ensino (Pi, Xu, Liu \& Yang, 2020).

As metodologias de avaliação do aprendizado dos estudantes estão passando por intensas fases de transformação sob os aspectos pedagógicos, pois a avaliação continuada tem o intuito de, gradativamente, diagnosticar e aperfeiçoar a aprendizagem dos alunos (Prata, 2003). A forma de avaliação é relevante no ensino superior, visto que os estudantes necessitam de autonomia para o desenvolvimento de habilidades e conhecimentos inerentes à formação (Lemos, 2011). Ainda, o desenvolvimento de processos para a avaliação do desempenho dos métodos de aprendizagem dos estudantes mediante as metodologias de ensino utilizadas precisam acompanhar as evoluções tecnológicas (Pi et al., 2020).

A literatura recomenda a utilização de estratégias de ensino em diferentes áreas do conhecimento, sobretudo em momentos adversos, quando as metodologias tradicionais carecem de adaptação ou implementação. Para melhor visualização, as principais estratégias de ensinoaprendizagem na área de Ciências Sociais Aplicadas são apresentadas na Tabela 1.

\section{Tabela 1}

\section{Principais estratégias de ensino}

\begin{tabular}{c|l}
\hline Estratégias & \multicolumn{1}{c}{ Apresentação } \\
\hline Aula expositiva dialogada & $\begin{array}{l}\text { "É uma exposição do conteúdo, com a participação ativa dos estudantes, cujo } \\
\text { conhecimento prévio deve ser considerado e pode ser tomado como ponto de } \\
\text { partida. O professor leva os estudantes a questionarem, interpretarem e } \\
\text { discutirem o objeto de estudo, a partir do reconhecimento e do confronto com a } \\
\text { realidade" (Anastasiou \& Alves, 2004, p. 79). }\end{array}$ \\
\hline \multirow{3}{*}{ Estudo de texto } & $\begin{array}{l}\text { É a exploração de ideias de um autor a partir do estudo crítico de um texto e/ou a } \\
\text { busca de informações e exploração de ideias de autores estudados (Anastasiou \& } \\
\text { Alves, 2004, p. 80). }\end{array}$ \\
\hline Tempestade cerebral & $\begin{array}{l}\text { É a identificação e a construção de registro, análise, seleção e reflexão das } \\
\text { produções mais significativas ou identificação dos maiores desafios/dificuldades } \\
\text { em relação ao objeto de estudo (Anastasiou \& Alves, 2004, p. 81). }\end{array}$ \\
\hline Mapa conceitual & $\begin{array}{l}\text { É uma possibilidade de estimular a geração de novas ideias de forma espontânea } \\
\text { e natural, deixando funcionar a imaginaça. Não há certo ou errado. Tudo o que } \\
\text { for levantado será considerado, solicitando-se, se necessário, uma explicação } \\
\text { posterior do estudante (Anastasiou \& Alves, 2004, p. 82). }\end{array}$ \\
\hline \multirow{2}{*}{$\begin{array}{l}\text { Estudo de texto ou estudo } \\
\text { dirigido e aulas orientadas }\end{array}$} & $\begin{array}{l}\text { uma perspectiva bidimensional, procurando mostrar as relaçães hierárquicas } \\
\text { entre os conceitos pertinentes à estrutura do conteúdo (Anastasiou \& Alves, } \\
\text { 2004, p. 83). }\end{array}$ \\
\hline
\end{tabular}


Resolução ou solução de problemas e de exercícios

Seminário

Estudo de caso

Júri simulado

Simpósio/painel/palestras/fórum

sob

Ba

Bain

Discussão e debate

Oficina (laboratório ou
workshop)

Escritório, laboratório ou empresa modelo

Ensino virtual

Exposições, excursões e visitas

p.

p. 37-38, Petrucci \& Batiston, 2006, p. 276-277).

Os alunos se tornam agentes do processo; são desenvolvidas habilidades na tomada de decisões no nível administrativo, vivenciando-se ações interligadas em Jogos de empresas $\quad$ ambientes de incerteza; permite a tomada de decisões estratégicas e táticas no gerenciamento dos recursos da empresa, sejam eles materiais ou humanos (Marion \& Marion, 2006, p. 50, Petrucci \& Batiston, 2006, p. 281-283). aplicação de princípios, leis que podem ou não ser expressas em fórmulas matemáticas. Estudo por meio de tarefas concretas e práticas tem por finalidade a assimilação de conhecimentos, habilidades e hábitos sob a orientação do professor (Anastasiou \& Alves, 2004, p. 86; Marion \& Marion, 2006, p. 46).

É uma estratégia particularmente válida em grandes turmas, pois consiste em separar a turma em pequenos grupos para facilitar a discussão. Assim, despertará no aluno a iniciativa de pesquisar, de descobrir aquilo que precisa aprender (Petrucci \& Batiston, 2006, p. 278-279).

É um espaço em que as ideias devem germinar ou ser semeadas. Portanto espaço onde um grupo discuta ou debata temas ou problemas que são colocados em discussão (Anastasiou \& Alves, 2004, p. 90).

É a análise minuciosa e objetiva de uma situação real que necessita ser 91).

É uma simulação de um júri em que, a partir de um problema, são apresentados argumentos de defesa e de acusação. Pode levar o grupo à análise e avaliação de um fato proposto com objetividade e realismo, à crítica construtiva de uma (Anastasiou \& Alves, 2004, p. 92).

É a reunião de palestras e preleções breves apresentada por várias pessoas (duas a cinco) sobre um assunto ou sobre diversos aspectos de um assunto. Possibilita o desenvolvimento de habilidades sociais, de investigação, amplia experiências sobre um conteúdo específico, desenvolve habilidades de estabelecer relações (Anastasiou \& Alves, 2004, p. 93; Marion \& Marion, 2006, p. 42; Petrucci \& Batiston, 2006, p. 288-289).

Sugere aos educandos a reflexão acerca de conhecimentos obtidos após uma leitura ou exposição, dando oportunidade aos alunos para formular princípios com suas próprias palavras, sugerindo a aplicação desses princípios (Marion \& Marion, 2006, p. 42-44)

É a reunião de um pequeno número de pessoas com interesses comuns, a fim de estudar e trabalhar para o conhecimento ou aprofundamento de um tema, sob orientação de um especialista. Possibilita o aprender a fazer melhor algo, mediante a aplicação de conceitos e conhecimentos previamente adquiridos (Anastasiou \& Alves, 2004, p. 96).

Proporciona ao aluno contato com a tecnologia da informação, os reflexos de má informação gerada, as inúmeras possibilidades de erros e os consequentes acertos (Petrucci \& Batiston, 2006, p. 286-288).

Também conhecido como $\mathrm{EaD}$, é uma modalidade de ensino através da necessidade do uso de ferramentas tecnológicas para que ocorra de maneira eficiente e impacte os acadêmicos de forma positiva no processo de aprendizagem (Ramdass \& Masithulela, 2016).

Participação dos alunos na elaboração do plano de trabalho de campo; possibilidade de integrar diversas áreas de conhecimento; inserção dos alunos na sociedade por meio de atividade integradas com as empresas; visualização, por parte do aluno, da teoria na prática; desenvolvimento do pensamento criativo do aluno e visão crítica da realidade em que ele se insere (Marion \& Marion, 2006,

Fonte: Adaptado de Mazzioni (2013).

claro: o que é a sessão, para que e como é preparada (Anastasiou \& Alves, 2004, p. 84; Petrucci \& Batiston, 2006, p. 279-280).

É o enfrentamento de uma situação nova, exigindo pensamento reflexivo, crítico e criativo a partir dos dados expressos na descrição do problema; demanda a . 
Os autores pesquisados relatam que as estratégias apresentadas não são únicas e absolutas, podem ser adaptadas utilizando-se ferramentas integradas para complementá-las, de acordo com a necessidade identificada pelo docente no processo de reconhecimento da aprendizagem por parte dos acadêmicos (Mazzioni, 2013). As estratégias de ensino escolhidas auxiliam na operacionalização dos resultados procurados (Liu, Geertshuis \& Grainger, 2020). Nesse cenário, os docentes dever formular suas estratégias de modo a suprir as diversas necessidades e maximizar os resultados do processo de ensino-aprendizagem.

Baartman, Bastiaens, Kirschner \& Vleuten (2007) indicam a importância da implementação de um Programa de Avaliação de Competências, o qual pode consistir em uma junção de diferentes métodos de avaliação, vinculado à definição dos critérios necessários para a análise da qualidade da relação ensino-aprendizagem (Dierick \& Dochy, 2001, Baartman et al., 2007).Destaca-se também que a utilização de uma única forma de avaliação é insuficiente para verificar e validar as competências dos acadêmicos (Gomes et al., 2012).

Nesse sentido, é necessário categorizar as estratégias de avaliação no ambiente virtual em cinco tipos de abordagem: a pedagogia, a didática, a ética, a psicologia e a tecnologia (Prata, 2003): a) a pedagogia está relacionada com a organização e estruturação da aprendizagem; b) a didática se relaciona à maneira e aos meios como o conhecimento é repassado para os acadêmicos; c) a ética está relacionada aos problemas éticos referentes à didática e a tecnologia de ensino; d) a psicologia faz referência à definição do perfil e acompanhamento emocional do acadêmico; e e) a tecnologia se refere à logística necessária para atender aos requisitos do ambiente de avaliação (Baartman et al., 2007).

Novas tecnologias e o acesso à informação permitiram inúmeros avanços no ambiente educacional, tanto na posição estratégica de buscar compreender as transformações do mundo quanto de produzir o conhecimento pedagógico sobre ele, além de auxiliar os usuários no cenário majoritariamente tecnológico (Alò, Castillo, Marín Vial, \& Samaniego, 2020). A crescente utilização das metodologias de ensino a distância fez que modelos de aprendizagem necessitassem de adaptações, consequentemente, as metodologias de avaliação também precisaram desses ajustes (Gomes et al., 2012). Esse movimento tem motivado o surgimento de estratégias inovadoras de avaliação, a maioria delas no ambiente digital (Amante, 2011). Porém a avaliação das atividades desenvolvidas em grupo, a avaliação desenvolvida entre pares e as diferentes formas de autoavaliação carecem de atenção e critérios de avaliação diferenciados entre o ambiente do ensino presencial e da EaD (Arora \& Srinivasan, 2020; Lall \& Singh, 2020).

O estudo de Silva (2019) evidencia as principais estratégias de ensino adequadas à didática do ensino superior. Entre elas, destacam: Aula Expositiva, Perguntas e Respostas, Estudo Dirigido, Fichas Didáticas, Método de Solução de Problemas, Método de Projetos, Trabalho em Grupo, Estudo in loco, Jogos, Dramatização, Seminário, Debate, Método da Descoberta e Unidades Didáticas. Tais estratégias são categorizadas como individuais, coletivas e mistas, bem como indicam que o uso dessas estratégias de ensino tem associação dos elementos didáticos: planejamento, organização de conteúdos, estratégias de ensino e avaliação.

A pesquisa de Arora e Srinivasan (2020) demonstrou os impactos do bloqueio no processo de ensino-aprendizagem, considerando a análise da adoção de classes virtuais ou a razão de não adotá-las. O estudo considerou as respostas de 341 professores de instituições de ensino superior. Os resultados indicam que a falta de conscientização é a principal razão para aqueles que não adotaram o $\mathrm{EaD}$, seguidos por falta de interesse e dúvidas sobre a utilidade das aulas virtuais, além da falta de interação devido a problemas de conectividade, sendo apontada como uma desvantagem significativa das aulas virtuais. $\mathrm{O}$ estudo também sugere maneiras de superar os desafios e os motivos por trás da não adoção ou utilização do EaD pelos professores do ensino superior.

De forma geral, pode-se destacar que as estratégias de ensino-aprendizagem, bem como o processo de avaliação independente do contexto do ensino presencial ou do ensino remoto 
emergencial, são impactados pelo surgimento de novas tecnologias de aprendizagem, exigindo adaptações e a interação dos docentes, visando tornar o aprendizado atrativo e adequado ao contexto social dos estudantes.

\section{PROCEDIMENTOS METODOLÓGICOS}

Este estudo se classifica como descritivo, realizado por meio de levantamento com abordagem mista, pelo qual tem objetivo de identificar as adaptações das estratégias no processo de ensino-aprendizagem, bem como as percepções docentes durante o isolamento social no contexto da pandemia gerada pela Covid-19.

A pesquisa foi realizada com instituições de ensino que, embora de forma não presencial, continuaram com as atividades pedagógicas diante da pandemia provocada pela Covid-19. Por questões de acesso aos professores respondentes, o questionário foi aplicado em quatro instituições de ensino superior, sendo: uma universidade comunitária que se divide em dois campus e três particulares de campus únicos. Quanto à localização geográfica, duas estão situadas no oeste catarinense e duas no sudoeste paranaense.

As participações foram obtidas a partir de levantamento operacionalizado por meio de questionário (Google Forms) disponibilizado de modo on-line, divulgado por e-mail aos professores, por meio do envio com a colaboração dos coordenadores dos cursos das quatro instituições de ensino. Ademais, a aplicação dos questionários foi restrita aos 91 professores que atuam em cursos da área de gestão e negócios nessas quatro instituições de ensino. Portanto o perfil dos respondentes é caracterizado por professores dos cursos de Administração, Ciências Contábeis e Ciências Econômicas que atuam em pelo menos uma disciplina em cursos de graduação presenciais.

O instrumento aplicado foi dividido em três blocos, sendo: Bloco I - Identificação dos respondentes, composto de 11 questões para categorização da amostra. Bloco II - Percepções docentes no processo de ensino-aprendizagem, composto por 15 questões mensuradas em escala tipo likert, as quais variam em cinco pontos: de " $1=$ Discordo Totalmente" a "5 - Concordo Totalmente". Por fim, o Bloco III - Estratégias de ensino-aprendizagem, é composto de seis questões, das quais duas são abertas permitindo a descrição dos docentes. O questionário foi elaborado e validado pelos pesquisadores, utilizando-se como pré-teste e validação o envio para cinco docentes. Posteriormente aos ajustes, o questionário foi aplicado na amostra de instituições que mantiveram o ensino remoto emergencial, justificando a seleção das IES. Identificou-se, nas quatro instituições de ensino, a quantidade de acadêmicos matriculados nos cursos da área de negócios. O curso de Administração é oferecido pelas quatro instituições e contempla o total de 698 acadêmicos, já o curso de Ciências Contábeis, que também é oferecido pelas quatro instituições, tem o total de 711 acadêmicos. Por fim, o curso de Ciências Econômicas apresenta 101 acadêmicos matriculados, sendo oferecido somente pela instituição de ensino comunitária, localizada no oeste catarinense. Portanto é possível identificar o total de 1.510 acadêmicos impactados diretamente pelas medidas de distanciamento social provocadas pela pandemia da Covid-19. Apresenta-se, na Tabela 2, a caracterização dos docentes respondentes que compõem a amostra do estudo.

A coleta de dados por meio de questionário foi realizada entre os dias 4 e 18 de maio de 2020, considerando a paralisação das atividades presenciais de ensino, conforme os decretos federais e estaduais. Obtiveram-se 52 respostas válidas de 91 possíveis respondentes da população que se encaixavam no perfil desejado pela pesquisa, o que caracteriza uma amostra de $57 \%$ da respectiva população de docentes. 
Tabela 2

\section{Caracterização dos respondentes}

\begin{tabular}{|c|c|c|c|c|c|}
\hline Gênero & Freq. & $\%$ & Tempo de atuação no ensino superior & Freq. & $\%$ \\
\hline Masculino & 26 & $50 \%$ & até 1 ano & 4 & $8 \%$ \\
\hline Feminino & 26 & $50 \%$ & entre 2 a 5 anos & 11 & $21 \%$ \\
\hline Total & 52 & $100 \%$ & entre 6 a 10 anos & 17 & $33 \%$ \\
\hline Maior Titulação & Freq. & $\%$ & entre 11 a 15 anos & 6 & $11 \%$ \\
\hline Especialização & 12 & $23 \%$ & 16 anos ou mais & 14 & $27 \%$ \\
\hline Mestrado & 11 & $21 \%$ & Total & 52 & $100 \%$ \\
\hline Doutorado & 29 & $56 \%$ & Carga horária de ensino semanal & Freq. & $\%$ \\
\hline Total & 52 & $100 \%$ & até 20 horas & 27 & $52 \%$ \\
\hline Idade & Freq. & $\%$ & entre 21 e 30 horas & 7 & $13 \%$ \\
\hline até 30 anos & 8 & $15 \%$ & entre 31 e 40 horas & 18 & $35 \%$ \\
\hline entre 31 e 40 anos & 13 & $25 \%$ & Total & 52 & $100 \%$ \\
\hline entre 41 e 50 anos & 24 & $46 \%$ & & & \\
\hline Acima de 51 anos & 6 & $12 \%$ & Quantidade de disciplinas & Freq. & $\%$ \\
\hline 61 anos ou mais & 1 & $2 \%$ & entre 1 e 2 disciplinas/componentes & 11 & $21 \%$ \\
\hline Total & 52 & $100 \%$ & entre 3 e 4 disciplinas/componentes & 18 & $35 \%$ \\
\hline Cursos de atuação & Freq. & $\%$ & entre 5 e 6 disciplinas/componentes & 18 & $35 \%$ \\
\hline Administração & 9 & $17 \%$ & entre 7 e 8 disciplinas/componentes & 5 & $10 \%$ \\
\hline Ciências Contábeis & 20 & $38 \%$ & Total & 52 & $100 \%$ \\
\hline Ciências Econômicas & 1 & $2 \%$ & Possui disciplinas no EAD? & Freq. & $\%$ \\
\hline Administração e C. Contábeis & 20 & $38 \%$ & Não & 36 & $69 \%$ \\
\hline C. Contábeis e C. Econômicas & 1 & $2 \%$ & Sim, 1 disciplina/componente & 7 & $13 \%$ \\
\hline Atuação nos três cursos & 1 & $2 \%$ & Sim, 2 a 3 disciplinas/componentes & 9 & $17 \%$ \\
\hline Total & 52 & $100 \%$ & Total & 52 & $100 \%$ \\
\hline
\end{tabular}

Nota. $\%=$ Percentual; Freq $=$ Frequência relativa; EAD = Ensino a Distância.

Fonte: Dados da pesquisa.

Para análise dos dados, empregou-se a estatística descritiva e testes estatísticos. $\mathrm{Na}$ estatística descritiva, analisou-se o mínimo, o máximo, a média, a moda, a mediana e o desviopadrão da amostra, enquanto, para o teste estatístico, foi utilizado o teste de U de Mann-Whitney em função de que os grupos de amostra são categorizados em duas amostras e estas se apresentam independentes entre si, considerando a orientação de Fávero \& Belfiore (2017), como uma técnica apropriada para o contexto da amostra pesquisada.

\section{ANÁLISE E INTERPRETAÇÃO DOS RESULTADOS}

Observando a caracterização da amostra de 52 docentes do estudo, $71 \%$ têm mais de seis anos de experiencia na docência no ensino superior, bem como $69 \%$ atuam apenas com o ensino presencial, 56\% são doutores e 70\% têm entre três e seis componentes/disciplinas no atual semestre 2020/1. Com objetivo de contextualizar as práticas de ensino-aprendizagem utilizadas pelos docentes das instituições de ensino, inicialmente, é necessário discutir os achados de dois questionamentos da pesquisa.

O primeiro deles tinha por objetivo identificar o andamento das atividades dos cursos de Administração, Ciências Contábeis e Ciências Econômicas, visando identificar se as instituições de ensino tinham mantido as aulas regularmente de forma remota. Foi questionado: "A partir do isolamento social, foi possível manter as atividades de todos os seus componentes/disciplinas?". Essa pergunta buscou evidenciar se alguma disciplina ou componente considerado prático (como 
a utilização de laboratórios, por exemplo) teve de ser interrompida. Dentre as 52 respostas obtidas, $96 \%$ dos pesquisados afirmaram que todas suas disciplinas/atividades estão ocorrendo de forma remota, somente dois respondentes afirmaram que foram mantidas apenas as aulas das disciplinas teóricas e as aulas práticas foram suspensas, perfazendo, assim, o total de $4 \%$ dos respondentes.

O segundo questionamento realizado para identificar o andamento das atividades de ensino nas instituições pesquisadas foi: "Com o contexto do isolamento social e a suspensão das atividades de ensino presenciais, indique as alternativas que identificam a realidade dos seus componentes/disciplinas) na instituição de ensino que atua". Para esta questão, os pesquisados poderiam optar por mais de uma opção simultaneamente. Sendo assim, 92\% dos respondentes informaram que foi possível manter as atividades e aulas de forma remota, com adaptações pedagógicas; $76 \%$ responderam que a instituição ofereceu capacitações pedagógicas e instrumentos para adequar as aulas de forma remota; e $40 \%$ dos professores pesquisados precisaram se adequar no encaminhamento de atividades aos estudantes, visando validar a carga horária da disciplina/componente curricular. Por fim, $4 \%$ afirmaram que as atividades práticas foram suspensas e as aulas teóricas foram adequadas para o ambiente virtual da instituição.

$\mathrm{Na}$ Tabela 3 são apresentados os valores obtidos na percepção dos docentes quanto às adequações das aulas no contexto da suspensão das atividades presenciais. As especificações apresentadas na Tabela 2 permitem identificar as variantes de cada percepção docente com base das respostas obtidas através de escala likert de 5 pontos, variando de " 1 = Discordo Totalmente" a "5 - Concordo Totalmente", observando-se a média e o desvio-padrão das respostas obtidas.

A pesquisa revelou que os docentes identificaram a percepção "PD6 - As aulas remotas evidenciam a possibilidade de adaptar metodologias de ensino" com a maior média entre todas as percepções docentes avaliadas, alcançando média de 4,10, com uma moda de 5. A segunda percepção docente que apresentou a maior média foi a "PD7 - Com as adaptações realizadas me surpreendi com a possibilidade das tecnologias e aprendi rapidamente alternativas pedagógicas", a qual obteve média de 4,00 com moda 4, com o menor desvio-padrão entre as percepções avaliadas. Os achados revelam que os docentes da amostra identificaram as aulas remotas como uma nova possibilidade de ensino e que não tiveram dificuldades para implantá-las, inclusive percebendo-as como alternativas pedagógicas.

Em relação às percepções docentes com menor influência no processo de ensinoaprendizagem, destacam-se a "PD3 - Uma das limitações é qualidade da internet, precisei melhorar o acesso para não prejudicar as atividades", a qual obteve média de 2,48 e moda 1 . O resultado demonstra que, de maneira geral, os professores possuem internet compatível para as aulas remotas. Entretanto não é possível generalizar este fato, pois esta foi a questão que obteve o maior desvio-padrão, o que também pode evidenciar dificuldades. A segunda percepção docente que se mostrou menos influente na visão dos docentes pesquisados foi a "PD1 - Senti dificuldades para adaptar os conteúdos e a forma remota das aulas", com média de 2,52 e desviopadrão relativamente baixo, conforme se observa na Tabela 3 , evidenciando que não houve dificuldades na adaptação das aulas presenciais para o formato remoto emergencial.

Outro aspecto observado na Tabela 3 se refere à condição "PD8 - As aulas remotas permitirão atingir os objetivos planejados para os componentes/disciplinas," com média de 3,83, mediana de 4 e desvio padrão de 1,150, o que evidencia a percepção de que poderão ocorrer prejuízos quanto aos objetivos do processo de ensino-aprendizagem. Esse questionamento se relaciona com a "PD5 - Com as adaptações das aulas e as atividades de forma remota, não haverá prejuízos no processo de ensino-aprendizagem," que obteve média 3,08, moda 3 e desviopadrão de 1,218, corroborando com a percepção de que o contexto das adaptações das aulas remotas possibilita a execução das atividades, porém $46 \%$ evidenciam que haverá prejuízos no processo de ensino-aprendizagem e que prejudicarão a execução dos objetivos propostos para os componentes/disciplinas. 
Tabela 3

Percepções em relação ao processo de ensino-aprendizagem

\begin{tabular}{|c|c|c|c|c|c|c|c|}
\hline ID & Descrição & Mínimo & Máximo & Média & Moda & Mediana & Desvio-Padrão \\
\hline PD1 & $\begin{array}{l}\text { Senti dificuldades para adaptar os } \\
\text { conteúdos e a forma remota das } \\
\text { aulas. }\end{array}$ & 1 & 5 & 2,52 & 2 & 2 & 1,196 \\
\hline PD2 & $\begin{array}{l}\text { A maior dificuldade é a falta de } \\
\text { interação dos estudantes, percebi } \\
\text { redução da participação e isso me } \\
\text { frustra. }\end{array}$ & 1 & 5 & 3,27 & 4 & 4 & 1,315 \\
\hline PD3 & $\begin{array}{l}\text { Uma das limitações é a qualidade da } \\
\text { internet. Precisei melhorar o acesso } \\
\text { para não prejudicar as atividades. }\end{array}$ & 1 & 5 & 2,48 & 1 & 2 & 1,540 \\
\hline PD4 & $\begin{array}{lccr}\text { As aulas } & \text { remotas } & \text { reduziram } & \text { a } \\
\text { participação } & \text { dos } & \begin{array}{c}\text { estudantes } \\
\text { e }\end{array} \\
\text { dificultam } & \text { a } & \text { percepção } & \text { do } \\
\text { aprendizado. } & & & \\
\end{array}$ & 1 & 5 & 3,27 & 4 & 4 & 1,374 \\
\hline PD5 & $\begin{array}{l}\text { Com as adaptações das aulas e as } \\
\text { atividades de forma remota, não } \\
\text { haverá prejuízos no processo de } \\
\text { ensino-aprendizagem. }\end{array}$ & 1 & 5 & 3,08 & 4 & 3 & 1,218 \\
\hline PD6 & $\begin{array}{l}\text { As aulas remotas evidenciam a } \\
\text { possibilidade de adaptar } \\
\text { metodologias de ensino. }\end{array}$ & 1 & 5 & 4,10 & 5 & 4 & 1,015 \\
\hline PD7 & $\begin{array}{l}\text { Com as adaptações realizadas, me } \\
\text { surpreendi com a possibilidade das } \\
\text { tecnologias e aprendi rapidamente } \\
\text { alternativas pedagógicas. }\end{array}$ & 1 & 5 & 4,00 & 4 & 4 & 1,010 \\
\hline PD8 & $\begin{array}{l}\text { As aulas remotas nos permitirão } \\
\text { atingir os objetivos planejados para } \\
\text { os componentes/disciplinas. }\end{array}$ & 1 & 5 & 3,83 & 5 & 4 & 1,150 \\
\hline
\end{tabular}

Nota. ID - Identificação, PD = Percepções Docentes.

Fonte: Dados da pesquisa.

Com objetivo de explorar os achados referentes às percepções docentes em relação aos acadêmicos no processo de ensino-aprendizagem, foram analisadas as variáveis estatísticas de média, mediana, mínimo, máximo e o desvio-padrão. Na Tabela 4 são apresentadas as percepções docentes em relação aos estudantes. A Tabela 4 discute as percepções docentes em relação aos estudantes, com base nas respostas obtidas através de escala likert de 5 pontos, variando de "1 = Discordo totalmente" a "5 - Concordo totalmente". Ou seja, como os professores observam a participação dos estudantes e sua relação no processo de ensinoaprendizagem durante a pandemia da Covid-19.

A percepção "PA2 - A maior dificuldade é a falta de interação, nem todos gostam de participar com imagem e fala" foi a única com média superior a quatro pontos, alcançando 4,02, evidenciando que alguns acadêmicos não ativam suas câmeras durante as aulas remotas e/ou não participam nos debates nem questionam sobre suas dúvidas no decorrer da aula. Essa indicação demonstra que o modelo das aulas de forma remota e a falta de interação dos estudantes se torna uma das principais dificuldades percebidas pelos docentes da amostra, especialmente ponderando as rotinas do ensino presencial, ao qual a maioria dos docentes estavam habituados.

A segunda percepção docente em relação aos estudantes com a maior média foi a "PA3 Uma das limitações é qualidade da internet, por vezes os estudantes não têm acesso ou têm acesso limitado", a qual obteve média de 3,96. Este resultado é oposto a percepção docente "PD3 
- Uma das limitações é qualidade da internet, precisei melhorar o acesso para não prejudicar as atividades" da Tabela 3. Ou seja, na percepção dos docentes, o acesso à internet dos professores é considerado melhor do que o acesso dos estudantes.

Tabela 4

\section{Percepções em relação aos estudantes}

\begin{tabular}{|c|c|c|c|c|c|c|c|}
\hline ID & Descrição & Mínimo & Máximo & Média & Moda & Mediana & Desvio-Padrão \\
\hline PA1 & $\begin{array}{l}\text { Os estudantes sentiram dificuldades } \\
\text { para se adaptar aos conteúdos e à } \\
\text { forma remota das aulas. }\end{array}$ & 1 & 5 & 3,38 & 4 & 4 & 0,973 \\
\hline PA2 & $\begin{array}{l}\text { A maior dificuldade é a falta de } \\
\text { interação, nem todos gostam de } \\
\text { participar com imagem e fala. }\end{array}$ & 1 & 5 & 4,02 & 4 & 4 & 0,980 \\
\hline PA3 & $\begin{array}{l}\text { Uma das limitações é qualidade da } \\
\text { internet, por vezes os estudantes não } \\
\text { têm acesso ou têm acesso limitado. }\end{array}$ & 1 & 5 & 3,96 & 4 & 4 & 1,028 \\
\hline PA4 & $\begin{array}{l}\text { As aulas remotas reduziram a } \\
\text { participação dos estudantes e, mesmo } \\
\text { com as atividades encaminhadas, } \\
\text { houve redução da qualidade das } \\
\text { entregas. }\end{array}$ & 1 & 5 & 3,10 & 4 & 3 & 1,225 \\
\hline PA5 & $\begin{array}{l}\text { Com as adaptações das aulas e as } \\
\text { atividades de forma remota, não } \\
\text { haverá prejuízos no processo de } \\
\text { ensino-aprendizagem. }\end{array}$ & 1 & 5 & 3,02 & 4 & 3 & 1,213 \\
\hline PA6 & $\begin{array}{l}\text { As aulas remotas evidenciam a } \\
\text { possibilidade de adaptar metodologias } \\
\text { de ensino e os estudantes se adaptaram } \\
\text { com facilidade. }\end{array}$ & 2 & 5 & 3,67 & 4 & 4 & 0,964 \\
\hline PA7 & $\begin{array}{l}\text { As aulas remotas permitirão que os } \\
\text { estudantes atendam aos objetivos } \\
\text { planejados } \\
\text { componentes/disciplinas. }\end{array}$ & 1 & 5 & 3,65 & 4 & 4 & 1,046 \\
\hline
\end{tabular}

Nota. ID - Identificação, PA = Percepções docentes em relação aos estudantes.

Fonte: Dados da pesquisa.

A percepção docente em relação aos estudantes "PA5 - Com as adaptações das aulas e as atividades de forma remota, não haverá prejuízos no processo de ensino-aprendizagem" obteve a menor média entre as percepções pesquisadas $(3,02)$. Esse resultado indica que, na visão dos docentes, as aulas remotas não cumprem os mesmos objetivos de ensino-aprendizagem das aulas presenciais. A segunda percepção docente com a menor média foi a "PA4 - As aulas remotas reduziram a participação dos estudantes e, mesmo com as atividades encaminhadas, houve redução da qualidade das entregas", com média de 3,10. Tal resultado demonstra que as aulas remotas não diminuíram a frequência/participação dos estudantes nem houve percepção de redução da qualidade das entregas de atividades realizadas por parte dos estudantes.

O instrumento da pesquisa também questionou os docentes sobre estratégias de ensinoaprendizagem utilizadas durante as aulas remotas. Foram elencadas oito estratégias discutidas na literatura, conforme estudo de Mazzioni (2013), para que os docentes indicassem quais estratégias estão sendo utilizadas no contexto das aulas realizadas de forma remota.

A Tabela 5 apresenta a relação das percepções dos docentes em relação aos impactos da Covid-19 no processo de ensino-aprendizagem com as estratégias de ensino utilizadas. Para execução do teste de Mann-Whitney da Tabela 5, foi utilizada a questão: "De forma geral, ponderando o contexto geral da Covid-19, qual a sua avaliação em relação aos prejuízos do 
processo de ensino-aprendizagem pelos estudantes?". O resultado deste questionamento foi relacionado com as oito estratégias de ensino-aprendizagem elencadas pelos docentes.

Os resultados do teste de Mann-Whitney da Tabela 5 demostram relevância estatisticamente significativa entre as estratégias de ensino "5 - Problematização/análise de casos de ensino", "7 - Debates (discussões em grupo)" e "8 - Quiz (uso de jogos)". Isso significa que os docentes que indicaram utilizar tais estratégias de ensino acreditam que os prejuízos da Covid-19 no processo de ensino-aprendizagem são irrelevantes, que será possível repor o conteúdo e atingir os objetivos desejados.

Tabela 5

\section{Estratégias de ensino utilizadas}

\begin{tabular}{|c|c|c|c|c|c|}
\hline $\begin{array}{l}\text { Estratégias de Ensino } \\
\text { em Aulas Remotas }\end{array}$ & $\begin{array}{l}\text { Média do } \\
\text { Ranking }\end{array}$ & $\begin{array}{c}\text { Soma de } \\
\text { Classificações }\end{array}$ & $\begin{array}{l}\text { U de Mann- } \\
\text { Whitney }\end{array}$ & $\mathbf{Z}$ & Sig. \\
\hline \multicolumn{6}{|c|}{ Estratégia de Ensino 1 - Aulas expositivas com apresentação de conteúdo em slides } \\
\hline $\begin{array}{l}\text { Não } \\
\text { Sim }\end{array}$ & $\begin{array}{l}31,00 \\
26,41\end{array}$ & $\begin{array}{c}31,00 \\
1.347,00\end{array}$ & 21,00 & $-0,314$ & 0,753 \\
\hline \multicolumn{6}{|c|}{ Estratégia de Ensino 2 - Exercícios práticos com resolução } \\
\hline $\begin{array}{l}\text { Não } \\
\text { Sim }\end{array}$ & $\begin{array}{l}28,90 \\
26,24\end{array}$ & $\begin{array}{c}144,50 \\
1.233,50\end{array}$ & 105,50 & $-0,391$ & 0,696 \\
\hline \multicolumn{6}{|c|}{ Estratégia de Ensino 3 - Estudo de caso (casos práticos) } \\
\hline $\begin{array}{l}\text { Não } \\
\text { Sim }\end{array}$ & $\begin{array}{l}25,91 \\
26,76\end{array}$ & $\begin{array}{l}414,50 \\
963,50\end{array}$ & 278,50 & $-0,198$ & 0,843 \\
\hline \multicolumn{6}{|c|}{ Estratégia de Ensino 4 - Análise de dados ou relatórios disponíveis para análise } \\
\hline $\begin{array}{l}\text { Não } \\
\text { Sim }\end{array}$ & $\begin{array}{l}25,58 \\
27,75\end{array}$ & $\begin{array}{l}767,50 \\
610,50\end{array}$ & 302,50 & $-0,534$ & 0,593 \\
\hline \multicolumn{6}{|c|}{ Estratégia de Ensino 5 - Problematização/análise de casos de ensino } \\
\hline $\begin{array}{l}\text { Não } \\
\text { Sim }\end{array}$ & $\begin{array}{l}21,39 \\
32,02\end{array}$ & $\begin{array}{l}577,50 \\
800,50\end{array}$ & 199,50 & $-2,651$ & 0,008* \\
\hline \multicolumn{6}{|c|}{ Estratégia de Ensino 6 - Pesquisas/leituras orientadas e estudos dirigidos sobre o conteúdo } \\
\hline $\begin{array}{l}\text { Não } \\
\text { Sim }\end{array}$ & $\begin{array}{l}23,30 \\
29,03\end{array}$ & $\begin{array}{l}536,00 \\
842,00\end{array}$ & 260,00 & $-1,42$ & 0,156 \\
\hline \multicolumn{6}{|c|}{ Estratégia de Ensino 7 - Debates (discussões em grupo) } \\
\hline $\begin{array}{l}\text { Não } \\
\text { Sim }\end{array}$ & $\begin{array}{l}19,57 \\
35,24\end{array}$ & $\begin{array}{l}567,50 \\
810,50\end{array}$ & 132,50 & $-3,903$ & $\mathbf{0 , 0 0 0 *}$ \\
\hline \multicolumn{6}{|c|}{ Estratégia de Ensino 8 - Quiz (uso de jogos) } \\
\hline $\begin{array}{l}\text { Não } \\
\text { Sim }\end{array}$ & $\begin{array}{l}21,83 \\
34,61\end{array}$ & $\begin{array}{l}720,50 \\
657,50\end{array}$ & 159,50 & $-3,084$ & 0,002 \\
\hline
\end{tabular}

Nota. * significância ao nível de 5\%.

Fonte: Dados da pesquisa.

De forma geral, como havia possibilidade de indicar mais de uma estratégia de ensinoaprendizagem utilizada, os resultados permitem evidenciar que, no processo de ensinoaprendizagem dos docentes que atuam nos cursos de Administração, Ciências Contábeis e Ciências Econômicas, as estratégias mais utilizadas são:

(i) Aulas expositivas com apresentação de conteúdo em slides - 98\%;

(ii) Exercícios práticos com resolução $-90 \%$;

(iii) Estudo de caso (casos práticos) - 69\%;

(iv) Análise de dados ou relatórios disponíveis para análise - 40\%;

(v) Problematização/análise de casos de ensino - 44\%;

(vi) Pesquisas/leituras orientadas e estudos dirigidos sobre o conteúdo - 52\%; 
(vii) Debates (discussões em grupo) - 42\%;

(viii) Quiz (uso de jogos) $-37 \%$.

Além das oito estratégias descritas na Tabela 5, havia possibilidade dos docentes indicarem outras estratégias ou ferramentas utilizadas em suas aulas remotas. Algumas das respostas mencionadas foram: "utilização de planilhas do Excel" (três menções); "participações remotas de convidados/profissionais externos" (duas menções); "mapas conceituais" (duas menções); "ferramentas do Google" (duas menções); "Kahoot" (duas menções). Além destas, foram mencionadas uma única vez: "distribuição/sorteio de perguntas para debates $e$ justificativas das respostas"; "pesquisa com empresas, por meio de WhatsApp, para coleta de informações"; "montagem de manuais para parametrização com passo a passo, antes isso era passado na prática", e "vídeos complementares do YouTube".

Outra observação evidenciada nesta pesquisa foi em relação ao meio de avaliação, que é uma etapa fundamental do processo de ensino-aprendizagem. Diante disso, foi questionado sobre quais as formas de avaliação estão sendo utilizadas durante a pandemia e, na sequência, questionou-se a percepção da sistemática de avaliação utilizada, se ela atendeu às expectativas de ensino-aprendizagem, cuja medida escalar era de "1 - Totalmente insuficiente" e "5 Totalmente suficiente". A Tabela 6 relaciona a percepção dos docentes em relação aos impactos da Covid-19 no processo de ensino-aprendizagem com as estratégias de avaliação utilizadas.

Tabela 6

Estratégias de avaliação utilizada

\begin{tabular}{|c|c|c|c|c|c|}
\hline $\begin{array}{l}\text { Estratégias de Avaliação } \\
\text { em Aulas Remotas }\end{array}$ & $\begin{array}{l}\text { Média do } \\
\text { Rank }\end{array}$ & $\begin{array}{l}\text { Soma de } \\
\text { Classificações }\end{array}$ & $\begin{array}{l}\text { U de Mann- } \\
\text { Whitney }\end{array}$ & $\mathbf{Z}$ & Sig. \\
\hline \multicolumn{6}{|c|}{ Estratégia de Avaliação 1 - As avaliações foram adaptadas para atividades com resolução com consulta } \\
\hline Não & 27,75 & 610,50 & \multirow{2}{*}{302,50} & \multirow{2}{*}{$-0,588$} & \multirow{2}{*}{0,556} \\
\hline Sim & 25,58 & 767,50 & & & \\
\hline \multicolumn{6}{|c|}{ Estratégia de Avaliação 2 - As avaliações foram adaptadas e utilizei mais questões descritivas } \\
\hline Não & 24,79 & 768,50 & \multirow{2}{*}{272,50} & \multirow{2}{*}{$-1,141$} & \multirow{2}{*}{0,254} \\
\hline Sim & 29,02 & 609,50 & & & \\
\hline \multicolumn{6}{|c|}{ Estratégia de Avaliação 3 - As avaliações ocorreram normalmente, mesmo que de forma remota } \\
\hline Não & 25,57 & 895,00 & \multirow{2}{*}{265,00} & \multirow{2}{*}{$-0,743$} & \multirow{2}{*}{0,458} \\
\hline Sim & 28,41 & 483,00 & & & \\
\hline \multicolumn{6}{|c|}{$\begin{array}{l}\text { Estratégia de Avaliação } 4 \text { - As avaliações ocorreram de forma remota com uso de tecnologias (sistema } \\
\text { embaralha questões, troca a ordem e limita retornar às questões) }\end{array}$} \\
\hline Não & 20,37 & 550,00 & \multirow{2}{*}{172,00} & \multirow{2}{*}{$-3,552$} & \multirow{2}{*}{ 0,000* } \\
\hline Sim & 33,12 & 828,00 & & & \\
\hline
\end{tabular}

Nota. * significância ao nível de $5 \%$.

Fonte: Dados da pesquisa.

Os resultados do teste de Mann-Whitney da Tabela 6 demostram relevância estatisticamente significativa entre a estratégia de avaliação " 4 - As avaliações ocorreram de forma remota com uso de tecnologias (sistema embaralha questões, troca a ordem e limita retornar às questões)". Esse resultado indica que os docentes que utilizaram desta estratégia de avaliação a consideram como a que tem maiores chances de atender de modo suficiente ao processo de avaliação do ensino-aprendizagem, pois a relação foi significativa entre a estratégia 4 e a relação de que o processo atendeu de modo "Totalmente suficiente". 
Quanto à utilização das estratégias de avaliação do processo de ensino-aprendizagem "1 As avaliações foram adaptadas para atividades com resolução com consulta"; identificou-se que $58 \%$ dos docentes indicaram esse formato de utilização; outros $40 \%$ indicam utilizar " 2 - As avaliações foram adaptadas e utilizei mais questões descritivas"; para 33\% dos docentes, "3 - As avaliações ocorreram normalmente, mesmo que de forma remota"; e $48 \%$ indicam que "4 - As avaliações ocorreram de forma remota com uso de tecnologias (sistema embaralha questões, troca a ordem e limita retornar às questões)". Para esse questionamento, os docentes poderiam selecionar mais de uma opção ou, ainda, descrever quais estratégias de avaliação foram utilizadas e não estavam citadas no questionário.

A análise realizada permitiu, por meio das respostas de uma das questões descritiva, identificar as maiores dificuldades dos docentes em relação às aulas e atividades de ensino no processo de isolamento social, como a falta de interação e/ou participação dos alunos, representando a percepção de $33 \%$ da amostra dos docentes, sendo uma das principais dificuldades notadas quanto ao contexto do isolamento social na execução das aulas do ensino presencial realizadas de forma remota.

Quanto ao contexto geral imposto pela Covid-19, 46\% dos docentes da amostra evidenciam a percepção de que haverá prejuízos no processo de ensino-aprendizagem dos estudantes (consideraram como relevantes), tendo em vista que não será possível repor e atingir os objetivos desejados, enquanto outros 54\% consideram irrelevantes e que não haverá prejuízos no processo de ensino-aprendizagem dos estudantes, sendo possível repor e atingir os objetivos desejados. Tais resultados corroboram com o estudo de Barbour et al. (2020), sugerindo que a maioria dos docentes compreende como possível a execução das atividades de ensino de forma remota emergencial sem maiores prejuízos no processo de aprendizagem. Estes achados são representativos, especialmente quando se observa que nem todos os docentes tinham experiências com o modelo de ensino remoto emergencial, e que a necessidade do uso das tecnologias imposta pela pandemia contribuirá com inovações nas estratégias de ensino-aprendizagem utilizadas pelos docentes da área de gestão e negócios, independentemente do modelo presencial ou remoto.

\section{CONSIDERAÇÕES FINAIS}

Este estudo teve como objetivo identificar as adaptações das estratégias do processo de ensino-aprendizagem, bem como as percepções docentes durante o isolamento social no contexto da pandemia gerada pela Covid-19, considerando a amostra de docentes dos cursos da área de gestão (Administração, Ciências Contábeis e Ciências Econômicas).

Os resultados indicam as percepções docentes em relação a sua própria atuação durante o isolamento social e à execução das aulas presenciais de forma remota. Os resultados evidenciam a percepção dos docentes quanto à possibilidade de adaptar metodologias de ensino e que, com essas adaptações, eles se surpreenderam com as possibilidades da inserção de tecnologias, assim como elas puderam ser rapidamente adaptadas pedagogicamente às disciplinas.

Quanto à percepção dos docentes em relação aos estudantes, os resultados indicam que a maior dificuldade encontrada nas aulas remotas foi a interação, pois nem todos os estudantes participam com vídeo e fala durante as aulas, dando a impressão de que a atividade era restrita a alguns estudantes da turma. Outra percepção dos docentes em relação aos estudantes é quanto à a limitação da qualidade de internet dos estudantes, o que dificulta o acesso e a participação ativa nas aulas de forma remota.

Foram observadas ainda as estratégias de ensino-aprendizagem utilizadas pelos docentes e quais destas convergem com o objetivo de atingir os objetivos da disciplina. Entre as estratégias utilizadas evidenciam-se as principais: (i) aulas expositivas com apresentação de 
conteúdo em slides - 98\%; (ii) exercícios práticos com resolução - 90\%; (iii) estudo de casos práticos - 69\%; e (iv) pesquisas/leituras orientadas e estudos dirigidos sobre o conteúdo - 52\%. Nesse sentido, a pesquisa evidenciou que os docentes que utilizaram problematização/análise de casos de ensino, debates (discussões em grupo) e quiz (uso de jogos) acreditam ter alcançado os objetivos de ensino-aprendizagem. Em relação ao processo de avaliação, os docentes que utilizaram tecnologias (sistema embaralha questões, troca a ordem e limita retornar às questões) também notaram que o processo de avaliação atingiu os objetivos esperados.

$\mathrm{O}$ estudo oferece contribuição não apenas para a literatura do processo de ensinoaprendizagem dos cursos da área de negócios (Administração, Ciências Contábeis e Ciências Econômicas), mas também contribui com os estudos relacionados à temática da Covid-19 que afetou o comportamento das pessoas de forma mundial, pois os desafios impostos pelo distanciamento social também afetaram o ensino presencial. Nesse sentido, o estudo pondera as percepções dos docentes do ensino superior, evidenciando que novas alternativas de aprendizagem e o uso de tecnologias podem ser rapidamente inseridos e adaptados ao processo de ensino-aprendizagem. Observou-se, inclusive, a possibilidade de interação e participação externa (convidados) como estratégia de ensino facilitada pelo modelo de ensino remoto. As percepções apresentadas sugerem que este período de pandemia contribuirá com inovações nas estratégias de ensino-aprendizagem, especialmente quanto ao uso das tecnologias pelos docentes da área de gestão e negócios, independentemente do modelo presencial ou remoto emergencial.

Para pesquisas futuras, sugere-se avaliar não apenas os impactos deixados pela Covid-19, como também novas ferramentas de ensino-aprendizagem e de avaliação do ensino que começarão a ser utilizadas a partir da pandemia e, também, quais delas estarão presentes no período pós-pandemia. Isso porque diversas tecnologias e metodologias de ensino-aprendizagem começaram a ser utilizadas e adaptadas pelos docentes do ensino presencial neste período.

\section{REFERÊNCIAS}

Abmes, Associação Brasileira de Mantenedoras de Ensino Superior. (2020, maio). Ensino a distância supera o presencial, e faculdades privadas adaptam negócios. Recuperado de https://abmes.org.br/noticias/detalhe/3601/ensino-a-distancia-supera-o-presencial-efaculdades-privadas-adaptam-negocios

Agência Brasil, 2020. Censo da Educação Superior em 2019. Recuperado de https://agenciabrasil.ebc.com.br/educacao/noticia/2020-10/censo-mostra-que-ensinodistancia-ganha-espaco-no-ensino-superior

Ali, S. A. A. \& Syed, S. (2020). Teaching and learning strategies of oral histology among dental students. International Journal of Morphology, 38(3) 634-639.

Alò, D., Castillo, A., Marín Vial, P. \& Samaniego, H. (2020). Low-cost emerging technologies as a tool to support informal environmental education in children from vulnerable public schools of southern Chile. International Journal of Science Education, 42(4), 635-655.

Alonso, K. M. (2010). A expansão do ensino superior no Brasil e a EaD: dinâmicas e lugares. Educação \& Sociedade, 31(113), 1319-1335. 
Amante, L. (2011). A Avaliação das Aprendizagens em Contexto Online: O e-portefólio como Instrumento Alternativo. In Paulo Dias \& António Osório (Orgs.). Aprendizagem (In)Formal na Web Social. Centro de Competência da Universidade do Minho, Braga, 221-236.

Anastasiou, L. G. C., \& Alves, L. P. (2004). Processos de ensinagem na universidade. Pressupostos para as estratégias de trabalho em aula. (3a ed.). Joinville: Univille.

Arora, A. K. \& Srinivasan, R. (2020). Impact of pandemic covid-19 on the teaching - learning process: A study of higher education teachers. Prabandhan: Indian Journal of Management. 13(4) 43-56.

Baartman, L., Bastiaens, T., Kirschner, P., \& Vleuten, C. (2007). Evaluating assessment quality in competence-based education: a qualitative comparison of two frameworks. Educational Research Review, 2, 114-129.

Barbour, M. K., LaBonte, R., Hodges, C., Moore, S., Lockee, B., Trust, T., ... \& Kelly, K. (2020). Understanding pandemic pedagogy: Differences between emergency remote, remote, and online teaching. State of the Nation: K-12 e-Learning in Canada.

Boruchovitch, E., Santos, A. A. A., Costa, E. R., Neves, E. R. C., Cruvinel, M. Primi, R., \& Guimarães, S. E. R. (2006). Estudo preliminar para construção de uma escala de estratégias de aprendizagem infantil. Psicologia: Teoria e Pesquisa, 22, 297-304.

Dierick, S., \& Dochy, F. (2001). New lines in edumetrics: new forms of assessment lead to new assessment criteria. Studies in Educational Evaluation, 27, 307-329.

Fávero, L. P., \& Belfiore, P. (2017). Manual de análise de dados: estatística e modelagem multivariada com Excel®, SPSS® e Stata®. Elsevier Brasil.

Halawa, S., Hsu, Y. S., Zhang, W. X., Kuo, Y. R., \& Wu, J. Y. (2020). Features and trends of teaching strategies for scientific practices from a review of 2008-2017 articles. International Journal of Science Education, 42(7), 1183-1206.

Hilliger, I., Ortiz-Rojas, M., Pesántez-Cabrera, P., Scheihing, E., Tsai, Y. S., Muñoz-Merino, P. J., Broos, T., Whitelock-Wainwright, A., \& Pérez-Sanagustín, M. (2020). Identifying needs for learning analytics adoption in Latin American universities: A mixed-methods approach. Internet and Higher Education, 45(100726), 1-17.

Gomes, M. J. G. J., Amante, L., \& Oliveira, I. (2012). Avaliação digital no ensino superior em Portugal: primeiros resultados. Revista Linhas, 13(2), 10-28.

Governo do Estado de Santa Catarina. (2020, maio). Coronavírus em SC: Governo do Estado estabelece sistema de trabalho para atividades escolares não presenciais. Recuperado de https://www.sc.gov.br/noticias/temas/coronavirus/coronavirus-em-sc-governo-do-estadoestabelece-sistema-de-trabalho-para-atividades-escolares-nao-presenciais

Kruger, S. D., Zanella, C., Barichello, R., \& Petri, S. M. (2018). Sustentabilidade: uma abordagem acerca das percepções dos acadêmicos de uma instituição de ensino superior de Santa Catarina. Revista Gestão Universitária na América Latina-GUAL, 11(3), 86-104. 
Lall, S., \& Singh, N. (2020). COVID-19: Unmasking the new face of education. International Journal of Research in Pharmaceutical Sciences, 11(1) 48-53.

Lemos, E. S. (2011). A aprendizagem significativa: estratégias facilitadoras e avaliação. Meaningful Learning Review, 1(1) 25-35.

Liu, Q., Geertshuis, S., \& Grainger, R. (2020). Understanding academics' adoption of learning technologies: A systematic review. Computers and Education, 151.

Marion, J. C., \& Marion, A. L. C. (2006). Metodologias de ensino na área de negócios. São Paulo: Atlas.

Mazzioni, S. (2013). As estratégias utilizadas no processo de ensino-aprendizagem: Concepções de alunos e professores de ciências contábeis. Revista Eletrônica de Administração e Turismo, 2(1) 93-109.

Mendoza, H. H., Burbano, V. M., \& Valdivieso, M. A. (2019). The role of the teacher of mathematics in virtual university education. A study in the Pedagogic and Technologic University of Colombia. Formacion Universitaria, 12(5) 51-60.

Ministério da Educação. (2020, maio). Educação Superior a Distância. Recuperado de http://portal.mec.gov.br/instituicoes-credenciadas/educacao-superior-a-distancia

Miles, D., Mensinga, J. B \& Zuchowski, I. (2018). Harnessing opportunities to enhance the distance learning experience of msw students: an appreciative inquiry process. Social Work Education, 37(6), 705-717.

Murray, A. (2019). Competition as a Teaching Strategy. BU Journal of Graduate Studies in Education, 11(1), 13-16.

Oliveira, Ê. S. (2017). Motivação no ensino superior: estratégias e desafios. Revista Contexto \& Educação, 32(101), 212-232.

Oliver, R. (1999). Exploring strategies for online teaching and learning. Distance Education, 20, 240-254.

Petrucci, V. B. C., \& Batiston, R. R. (2006). Estratégias de ensino e avaliação de aprendizagem em contabilidade. In I. R. Peleias (Org.). Didática do ensino da contabilidade. São Paulo: Saraiva.

Pi, Z., Xu, K., Liu, C., \& Yang, J. (2020). Instructor presence in video lectures: Eye gaze matters, but not body orientation. Computers and Education, 144(103713), 1-8.

Prata, D. N. (2003). Estratégias para o Desenvolvimento de um Framework de Avaliação da Aprendizagem a Distância. Anais do Simpósio Brasileiro de Informática na Educação, 146$155,14$.

Ramdass, K., \& Masithulela, F. (2016). Comparative analysis of pedagogical strategies across disciplines in open distance learning at unisa. International Review of Research in Open and Distance Learning, 17(2), 1-18. 
Rossoni, L. (2020). Covid-19, Organizações, Trabalho em Casa e Produção Científica. Revista Eletrônica de Ciência Administrativa, 19(2), 158-168.

Silva, J. F. da. (2019). Didática no Ensino Superior: estratégias de ensino adequadas à arte de ensinar. Educação Por $\quad$ Escrito, 9(2), 204-219. https://doi.org/10.15448/21798435.2018.2.31275

Stobaugh, R., \& Everson, K. (2019). Student Teacher Engagement in Co-Teaching Strategies. Educational Renaissance, 8, 30-47.

Sun, Q., Qiu, H., Huang, M., \& Yang, Y. (2020). Lower mortality of COVID-19 by early recognition and intervention: experience from Jiangsu Province. Annals of Intensive Care. $10(33) 1-4$.

Taraban, R., Rynearson, K., \& Kerr, M. (2000). College students academic performance and self-reports of comprehension strategy use. Reading Psychology, 21, 283-308.

Tinajero, C., Lemos, S. M., Araújo, M., Ferraces, M. J., \& Páramo, F. (2012). Estilo cognitivo e estratégias de aprendizagem em estudantes universitários brasileiros: Repercussões no rendimento acadêmico. Psicologia: Reflexão e Crítica, 25(1), 105-113.

Unesco, United Nations Educational, Scientific and Cultural Organization. (2020, maio). Coronavirus Covid-19 and higher education: impact and recommendations. Recuperado de http://www.iesalc.unesco.org/en/2020/03/09/coronavirus-covid-19-and-higher-educationimpact-and-recommendations/.

Zanella, C., Krüger, S. D., \& Barichello, R. (2019). Sustentabilidade: uma abordagem das percepções de professores do ensino superior. Revista de Administração IMED, 9(2), 73-93. 